Article

\title{
Facile Synthesis of "Boron-Doped" Carbon Dots and Their Application in Visible-Light-Driven Photocatalytic Degradation of Organic Dyes
}

\author{
Zhili Peng ${ }^{1,+}{ }^{\oplus}$, Yiqun Zhou ${ }^{2, \dagger}$, Chunyu Ji ${ }^{1}$, Joel Pardo ${ }^{2}$, Keenan J. Mintz ${ }^{2}{ }^{\oplus}$, Raja R. Pandey ${ }^{3}$, \\ Charles C. Chusuei ${ }^{3} \mathbb{D}$, Regina M. Graham ${ }^{4} \mathbb{D}$, Guiyang Yan ${ }^{5,6, *}$ and Roger M. Leblanc ${ }^{2, *}$ \\ 1 National Center for International Research on Photoelectric and Energy Materials, School of Materials and \\ Energy, Yunnan University, Kunming 650091, China; zhilip@ynu.edu.cn (Z.P.); \\ jichunyu@mail.ynu.edu.cn (C.J.) \\ 2 Department of Chemistry, University of Miami, 1301 Memorial Drive, Coral Gables, FL 33146, USA; \\ yxz431@miami.edu (Y.Z.); joelpardo24@gmail.com (J.P.); kjm154@miami.edu (K.J.M.) \\ 3 Department of Chemistry, Middle Tennessee State University, Murfreesboro, TN 37132, USA; \\ RajaRam.Pandey@mtsu.edu (R.R.P.); Charles.Chusuei@mtsu.edu (C.C.C.) \\ 4 Department of Neurological Surgery, Miller School of Medicine, University of Miami, Miami, FL 33136, USA; \\ rgraham@med.miami.edu \\ 5 Key Laboratory of Green Energy and Environment Catalysis (Ningde Normal University), \\ Fujian Province University, Ningde 352100, China \\ 6 Fujian Provincial Key Laboratory of Featured Biochemical and Chemical Materials, \\ Ningde Normal University, Ningde 352100, China \\ * Correspondence: ygyfjnu@163.com (G.Y.); rml@miami.edu (R.M.L.); \\ Tel.: +86-13809566652 (G.Y.); +1-305-284-2194 (R.M.L.) \\ + These authors contributed equally to this work.
}

Received: 13 July 2020; Accepted: 6 August 2020; Published: 8 August 2020

check for updates

\begin{abstract}
Carbon dots (C-dots) were facilely fabricated via a hydrothermal method and fully characterized. Our study shows that the as-synthesized C-dots are nontoxic, negatively charged spherical particles (average diameter $4.7 \mathrm{~nm}$ ) with excellent water dispersion ability. Furthermore, the C-dots have a rich presence of surface functionalities such as hydroxyls and carboxyls as well as amines. The significance of the C-dots as highly efficient photocatalysts for rhodamine B (RhB) and methylene blue (MB) degradation was explored. The C-dots demonstrate excellent photocatalytic activity, achieving $100 \%$ of $\mathrm{RhB}$ and $\mathrm{MB}$ degradation within $170 \mathrm{~min}$. The degradation rate constants for RhB and MB were $1.8 \times 10^{-2}$ and $2.4 \times 10^{-2} \mathrm{~min}^{-1}$, respectively. The photocatalytic degradation performances of the $\mathrm{C}$-dots are comparable to those metal-based photocatalysts and generally better than previously reported C-dots photocatalysts. Collectively considering the excellent photocatalytic activity toward organic dye degradation, as well as the fact that they are facilely synthesized with no need of further doping, compositing, and tedious purification and separation, the C-dots fabricated in this work are demonstrated to be a promising alternative for pollutant degradation and environment protection.
\end{abstract}

Keywords: carbon dots; photo catalysis; dye degradation; environment clean; rhodamine B; methylene blue

\section{Introduction}

The contamination of water bodies by organic dyes has quickly become a worldwide environmental concern [1]. Organic dyes are by-products of textile, printing, and plastic industries, which could damage aquatic ecosystems by suppressing light penetration and affecting photosynthesis. Furthermore, 
they can also lead to serious health issues such as cancer, birth defects, as well as hormone imbalances if ingested [2,3]. Unfortunately, the effective degradation of these dyes is rather difficult with traditional techniques due to their wide spreading and low concentration, as well as stable chemical nature. As a result, there is a key interest and necessity to seek innovative and viable approaches that could degrade organic dyes with high efficiency and practicality. Among the various approaches, photocatalytic dye degradation has emerged as one of the most efficient, practical, clean, and cost-effective methods, which only requires photocatalysts and light irradiation [4].

Nanomaterials derived from $\mathrm{TiO}_{2}$ have been regarded as promising photocatalysts for hydrogen generation via water splitting and environmental purification since the ground-breaking report by Honda and Fujishima in 1972 [5]. Especially after Carey et al. reported the first use of nano- $\mathrm{TiO}_{2}$ to degrade polychlorobiphenyls under ultraviolet (UV) irradiation in 1976 [6], various metal oxide-based photocatalysts, including $\mathrm{TiO}_{2}$ [7-12], $\mathrm{ZnO}$ [13-16], $\mathrm{Bi}_{2} \mathrm{O}_{3}$ [17-19], $\mathrm{Cu}_{2} \mathrm{O}$ [20,21], $\mathrm{Fe}_{2} \mathrm{O}_{3}$ [22,23], and $\mathrm{NiO} / \mathrm{Ni}(\mathrm{OH})_{2}[24,25]$ have been developed for the photocatalytic degradation of organic dyes and pollutants. However, most of the catalysts were metal-based, which pose a potential risk of secondary pollution to water bodies [26]. In addition, these catalysts often require multi-step synthesis, which is time-consuming and cost demanding [27-31]. Most importantly, most of the metal-based catalysts, due to their relatively large band gaps, can only utilize UV light that only accounts for a tiny fraction of the sunlight irradiation [32]. As such, these shortcomings have significantly limited the practical applications of metal-based photocatalysts. Therefore, much effort has been devoted for developing novel photocatalysts that are nontoxic, stable, able to utilize visible light, and have facile synthesis.

Carbon dots (C-dots) are the newest member of the renowned carbon-based nanomaterials family. Since their discovery in the early 2000s, they have been regarded as the green alternatives of the traditional, semiconductor-based quantum dots (QDs) with the most potential [33-36]. In the past decades, C-dots have been widely applied in various fields including chemistry, physics, engineering and biomedicine due to their superior properties such as high photoluminescence (PL) and stability, low toxicity, high biocompatibility, excellent water dispersion ability, as well as rich and tunable surface functionalities [37-42]. Even though the exact PL mechanism of C-dots is still under debate [43,44], researchers have drawn the general conclusion that $\mathrm{C}$-dots could be regarded as semiconductors that could generate electrons and holes under light irradiation. Due to the wide presence of tunable surface functionalities (i.e., surface states), the band gaps of C-dots are not locked strictly based on the energy difference of valence and conduction bands; instead, the band gaps could be tuned by the energy differences between the surface states and the valence band [45]. As a result, the potential applications of C-dots in driving photocatalytic redox reactions have been heavily investigated [46]. Unfortunately, C-dos alone have shown little activity toward the photocatalytic degradation of organic dyes [47-52]. To realize the efficient degradation of organic dyes, C-dots have to be integrated in metal-based heterostructures [50-57]. Recently, some encouraging reports demonstrated the efficient photocatalytic degradation of organic dyes by C-dots alone [58-64]; however, various factors including limited light absorption, extra surface doping, and tedious separation significantly limited their practical applications.

Herein, in this paper, we report a simple hydrothermal method for the fabrication of C-dots from citric acid (CA) and 1,2-diboranyethane (DBE). The C-dots are facilely synthesized in one-step, nontoxic, and highly photostable. Most importantly, they demonstrate excellent photocatalytic activity toward the degradation of methylene blue (MB) and rhodamine B (RhB) under visible light irradiation. The determined dye degradation efficiency and rate constants catalyzed by this C-dots alone are comparable to those metal-based heterostructures and generally better than other C-dots photocatalysts reported in the literature. The $\mathrm{C}$-dots prepared in this work are shown to be a very promising alternative for dye degradation and environment cleanliness. 


\section{Materials and Methods}

\subsection{Chemicals and Materials}

Citric acid, 1, 2-diboranyethane, rhodamine B, methylene blue, and N, N-dimethylformamide (DMF, anhydrous, 99.8\%) were purchased from Sigma-Aldrich (St. Louis, TX, USA). Argon gas was bought from Airgas (Miami, FL, USA). All chemicals were used as received without further purification unless otherwise noted. Purified water, with a surface tension of $72.6 \mathrm{mN} \cdot \mathrm{m}^{-1}$ and a resistivity of $18 \mathrm{M} \Omega \cdot \mathrm{cm}$ at $20.0 \pm 0.5^{\circ} \mathrm{C}$, was obtained from a Modulab 2020 water purification system (San Antonio, TX, USA). Dialysis bags with a molecular weight cutoff (MWCO) of 1000 were purchased from Thermo Scientific (Rockford, TX, USA). CellTiter 96 Aqueous One Solution Cell Proliferation Assay (MTS) was obtained from Promega (Madison, WI, USA).

\subsection{Synthesis of C-Dots}

The C-dots used in this study were prepared via a hydrothermal method. Briefly, $1 \mathrm{~g}$ of citric acid was quickly transferred to a Teflon-lined autoclave $(50 \mathrm{~mL})$; then 1 , 2-diboranyethane $(0.3 \mathrm{~g})$ was also quickly added, and after that, $20 \mathrm{~mL}$ of anhydrous DMF were introduced into the mixture. All of the above steps were carried out under argon gas protection. The autoclave was purged with argon gas for $5 \mathrm{~min}$, and then it was sealed and heated at $160{ }^{\circ} \mathrm{C}$ for $6 \mathrm{~h}$. After that, it was allowed to cool down naturally. The resulted reaction mixture was centrifuged for $15 \mathrm{~min}$ at $3000 \mathrm{rpm}$ to remove any large particles; then, the supernatant was subjected to dialysis with a semi membrane dialysis bag (MWCO 1000) against pure water for 3 days, with the water changed every $4 \mathrm{~h}$ during the day. C-dots in brownish powder form were obtained after the removal of water.

\subsection{Characterizations of C-Dots}

UV-Vis absorption spectra were obtained using a Cary 100 UV-Vis spectrophotometer (Agilent Technologies, Santa Clara, CA, USA) with a $1 \mathrm{~cm}$ optical path length cell; the absorption of C-dots was measured using an aqueous (deionized water) solution of C-dots at $1.25 \mathrm{mg} / \mathrm{mL}$. Fourier-transform infrared (FTIR) spectra were taken with a PerkinElmer FTIR (Frontier, Waltham, MA, USA) spectrometer using the attenuated total reflection (ATR) technique with air as background, and about $5 \mathrm{mg}$ of powder C-dots were used, which were recovered later on. Fluorescence spectra were measured by a fluorescence spectrophotometer (Horiba Jobin Yvon Fluorolog-3, Kyoto, Japan) at $25{ }^{\circ} \mathrm{C}$ with a slit width of $5 \mathrm{~nm}$ for both excitation and emission, an aqueous (deionized water) solution of C-dots at $1.25 \mathrm{mg} / \mathrm{mL}$ was used for the measurements. To evaluate the photostability of our C-dots under ambient light, C-dots solutions $(1.25 \mathrm{mg} / \mathrm{mL}) \mathrm{was}$ placed on a bench top exposed to room light. Their fluorescence emissions were tested at different intervals $(1,3,7,14,21,30,60$, and 90 days). X-ray photoelectron spectra (XPS) were acquired using a Perkin-Elmer PHI (Waltham, MA, USA) 560 system with a double-pass cylindrical mirror analyzer operated using a $\mathrm{Mg} \mathrm{K} \alpha$ anode with an $\mathrm{h} v=1253.6 \mathrm{eV}$ photon energy operated at $250 \mathrm{Watts}$ and $13 \mathrm{kV}$. Roughly 8 mg of "B-doped" C-dots samples were mounted as a paste onto a custom Ta foil sample holder and inserted into the XPS system via a turbopumped antechamber. Transmission electron microscopy (TEM) was performed on a JEOL 1200X TEM (Tokyo, Japan). Samples for TEM measurements were prepared as follows: C-dots were dissolved in deionized water to make a $0.1 \mathrm{mg} / \mathrm{mL}$ solution, and then the solution was sonicated for $30 \mathrm{~min}$ before a small drop of the solution was put onto a carbon-coated 200 mesh copper grid (EM Sciences Catalog \#CF200-CU). Then, the grid containing the drop of sample was put in a small Petri dish on a small piece of parafilm and allowed to dry overnight before it was used for measurement. Atomic force microscopy (AFM) was obtained on an Agilent 5420 atomic force microscope (Santa Clara, CA, USA) with the tapping mode. The samples were prepared as follows: C-dots were dissolved in deionized water to make a $0.1 \mathrm{mg} / \mathrm{mL}$ solution; then, the solution was sonicated for $30 \mathrm{~min}$ before a small drop of the solution was put onto a sample slide. Then, 3-5 drops of water were carefully dropped to the silica mica slide to dilute the sample further. Then, the slide 
containing the diluted sample was put in a small Petri dish on a small piece of parafilm and allowed to dry overnight before it was used for measurement. The zeta potential of the aqueous dispersion of the samples $(1.25 \mathrm{mg} / \mathrm{mL})$ were analyzed using a Zetasizer Nano ZS System (Malvern, Inc., Malvern, UK) with irradiation from a standard $633 \mathrm{~nm}$ laser at $25^{\circ} \mathrm{C}$.

\subsection{C-Dots Quantum Yield Determination}

The quantum yield was calculated based on the following equation (the relative method):

$$
\Phi=\Phi_{S} \times \frac{I}{I_{S}} \times \frac{A_{S}}{A} \times \frac{n^{2}}{n_{S}^{2}} \times \frac{D}{D_{S}}
$$

where $\Phi_{S}$ is the quantum yield of the standard sample; $I_{S}$ and $I$ are the integrated area under the emission peaks of the standard and unknown samples, respectively; $A_{S}$ and $A$ are the absorbance of the excitation wavelengths of the standard and unknown samples, respectively; $\mathrm{n}_{S}$ and $\mathrm{n}$ are the refractive indices of the standard and unknown samples, respectively; and $D / D_{S}$ is the dilution ratio if the samples are diluted during the measurement of fluorescence emission. In this experiment, UV-Vis absorption and the fluorescence emission spectra of $\mathrm{C}$-dots were recorded using deionized water as the solvent. Quinine sulfate in $0.1 \mathrm{M} \mathrm{H}_{2} \mathrm{SO}_{4}$ (quantum yield: 0.54) was used as the standard for quantum yield calculation. The refractive index of water is 1.333 and for $0.1 \mathrm{M} \mathrm{H}_{2} \mathrm{SO}_{4}$, it is 1.346 .

\subsection{Cell Viability/Proliferation Assay}

The viability of mesenchymal stem cells (non-cancer cells) was determined based on the MTS assay as previously described [65,66]. Briefly, $24 \mathrm{~h}$ prior to C-dots treatment, 5000-10,000 cells per well were plated into 96-well plates. Subsequently, the cells were treated with different concentrations $(0.0,0.1,1,10$, and $50 \mu \mathrm{g} / \mathrm{mL})$ of C-dots. The cell viability was analyzed after $72 \mathrm{~h}$ exposure to the C-dots using the CellTiter $96{ }^{\circledR}$ Aqueous One Solution Cell Proliferation Assay according to the manufacturer's instruction. Experiments were repeated at least three times, and data are presented as the average of the separate experiments. Viability was calculated as a percentage of the non-treated cells (i.e., concentration of C-dots is $0 \mu \mathrm{g} / \mathrm{mL}$ ).

\subsection{Photocatalytic Degradation of Organic Dyes}

$\mathrm{RhB}$ and MB are selected as model dyes to evaluate the photocatalytic ability of our C-dots in this study. Briefly, $3 \mathrm{mg}$ of C-dots and $0.2 \mathrm{~mL}$ of aqueous $\mathrm{RhB}(10 \mathrm{mg} / \mathrm{L})$ solution were mixed, and then $3.8 \mathrm{~mL}$ of deionized water were added. The resulted mixture (final concentration of RhB, $0.5 \mathrm{mg} / \mathrm{L}$ ) was transferred to an UV-Vis cuvette and ultrasonicated for $2 \mathrm{~min}$ to disperse the C-dots under dark. Then, the cuvette, vigorously stirred at $200 \mathrm{rpm}$, was placed in front of the solar simulator (Oriel Instruments, Newport Corporation) with high power mercury-xenon light source set at $310 \mathrm{~W}$ (see Supporting Information, Figure S1 for the spectrum of the lamps used). The UV-Vis absorption spectra of RhB were checked every 10 min under irradiation to monitor the degradation of RhB. Similar procedures were carried out for $\mathrm{MB}$ except that the amount of $\mathrm{MB}$ used was different. Instead of $0.2 \mathrm{~mL}, 1.0 \mathrm{~mL}$ of aqueous MB (10 mg/L) solution was mixed with $3 \mathrm{mg}$ of C-dots. As a result, only $3 \mathrm{~mL}$ of deionized water was used later to make the desired mixture solution for test (final concentration of $\mathrm{MB}, 2.5 \mathrm{mg} / \mathrm{L}$ ). Same procedures as for RhB were carried out to study and monitor the photocatalyzed degradation of MB by C-dots under light irradiation.

\section{Results}

The fabrication of C-dots from CA and ethylenediamine (EDA) is a very classical, facile bottom-up approach to prepare $\mathrm{C}$-dots, in which CA is considered as the main carbon precursor and EDA is the nitrogen-doping agent $[67,68]$. To explore the potential effects of boron doping on the properties of this type of C-dots $[69,70]$, we replaced EDA with DBE in the synthesis, in which the nitrogen atoms were 
replaced with boron atoms (Supporting Information, Figure S2). Excitingly, hydrothermal treatment of CA and DBE at $160{ }^{\circ} \mathrm{C}$ for $6 \mathrm{~h}$ produced the desired C-dots (herein named as "B-doped" C-dots). The reaction was carried out with anhydrous DMF as solvent in an argon atmosphere in order to minimize the hydrolysis of DBE, which is prone to hydrolysis due to the presence of borane functions. Interestingly, N-doped C-dots prepared from CA and EDA are a colorless gel-like form [67], while the "B-doped" C-dots in this study are brownish powder. To further analyze the morphological, physical, and chemical properties, characterizations of the "B-doped" C-dots by TEM and AFM microscopy, UV-Vis, FTIR, fluorescence, and XPS spectroscopy, as well as zeta potential were performed.

TEM and AFM microscopy were first applied to explore the morphologies and structural characteristics of the "B-doped" C-dots. The TEM image of C-dots (Figure 1A) shows that they are well-dispersed spherical particles with no obvious agglomerates. There are no noticeable lattices in these C-dots (Figure 1a, left inset), indicating that they have amorphous cores, instead of graphitic ones. These particles range from 2.5 to $7.0 \mathrm{~nm}$ in diameters with an average of $4.7 \mathrm{~nm}$ (Figure 1a, right inset). As shown in AFM images (Figure 1b), these particles are also evenly distributed with no noticeable agglomerates; the spherical particles are about 2.5-5.0 $\mathrm{nm}$ in height (Figure 1c), which is consistent with the diameter distributions obtained from TEM images. In summary, microscopic studies show that the "B-doped" C-dots (average diameter $4.7 \mathrm{~nm}$ ) are slightly larger in size than their counterparts synthesized from CA and EDA (average diameter $3.0 \mathrm{~nm}$ ) [71].

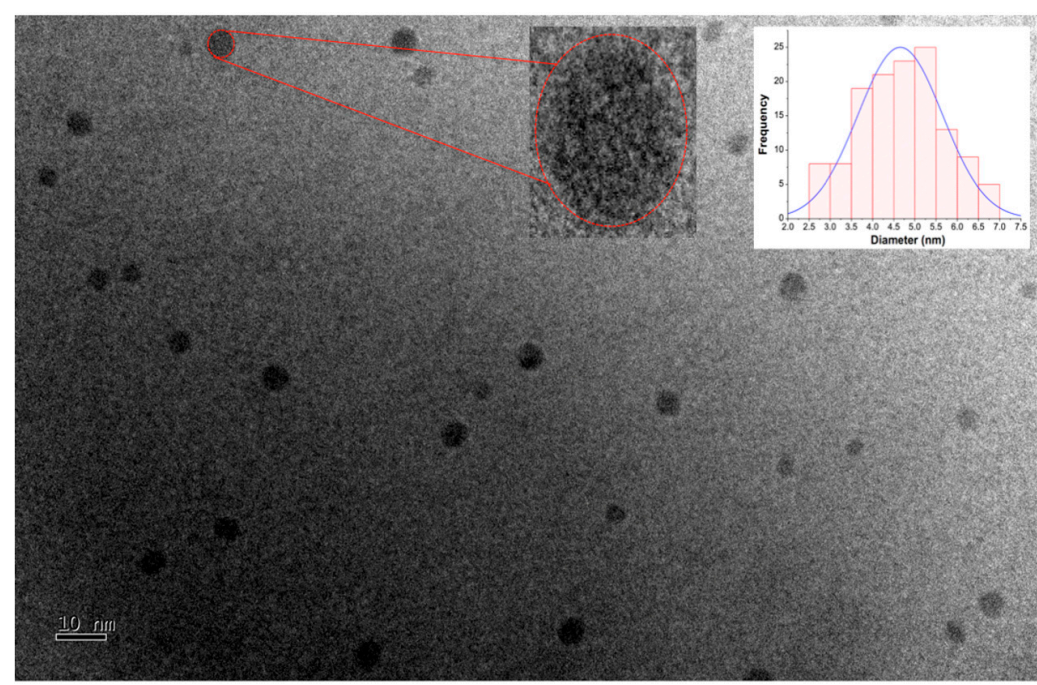

(a)
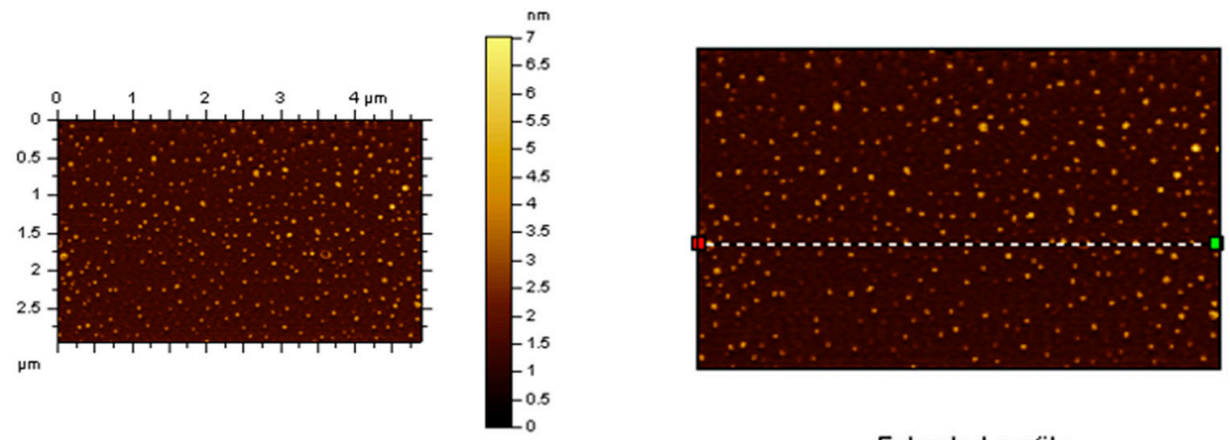

Extracted profile

(b)

Figure 1. Cont. 


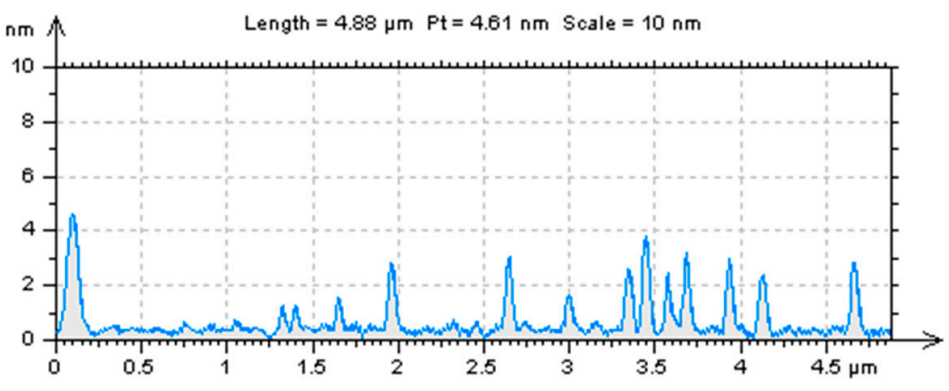

(c)

Figure 1. Morphological characterizations of "B-doped" C-dots: (a) TEM image of C-dots, the left inset is the enlarged image of one particle and the right inset is the size distribution histogram of C-dots; (b) atomic force microscopy (AFM) image of C-dots; (c) height profile of C-dots corresponding the profile line in Figure 1b.

Spectroscopic characterization techniques such as UV-Vis, FTIR, fluorescence, and XPS were then applied to explore the functionalities, chemical compositions, and PL behaviors of the "B-doped" C-dots. The UV-Vis absorption spectrum (Figure 2a) displays two typical peaks at 241 and $353 \mathrm{~nm}$, which corresponds to $\pi-\pi^{*}$ and $n-\pi^{*}$ transitions, indicating the presence of $C=C$ and $\mathrm{C}=\mathrm{O}$ bonds in the conjugate structures, respectively $[67,72]$. To further explore the functionalities, FTIR spectroscopy equipped with ATR accessories was performed. In the FTIR spectroscopy (Figure 2B), various functional groups such as $\mathrm{OH}$ and $\mathrm{NH}\left(3377-3250 \mathrm{~cm}^{-1}\right), \mathrm{CH}\left(2916 \mathrm{~cm}^{-1}\right), \mathrm{C}=\mathrm{O}(1648$ $\left.\mathrm{cm}^{-1}\right), \mathrm{C}=\mathrm{C}\left(1569 \mathrm{~cm}^{-1}\right), \mathrm{C}-\mathrm{H}\left(1393 \mathrm{~cm}^{-1}\right), \mathrm{C}-\mathrm{O}\left(1013 \mathrm{~cm}^{-1}\right)$, and $\mathrm{O}-\mathrm{H}\left(948 \mathrm{~cm}^{-1}\right)$ are observed, indicating the rich presence of functionalities such as hydroxyls, amines, and carbonyls as well as carboxyls [72,73]. These functionalities are further confirmed by XPS spectroscopy, which reveals $75.8 \%$ carbon, $19.1 \%$ oxygen and $5.1 \%$ nitrogen on the C-dots surface (Supporting Information, Table S1).

It is worth mentioning that we did not observe any B 1s core level signal in the XPS spectroscopy after several attempts. Interestingly, similar observations have been reported, in which some doping elements were not found in the "doped" C-dots. For instance, in Nabid and co-workers' report [74], boron was hardly found in C-dots prepared from hydrothermal treatment at $160^{\circ} \mathrm{C}$ using citric acid monohydrate as the carbon source, dicyandiamide and boric acid as nitrogen and boron-doping agents, respectively. In a different study, $\mathrm{Wu}$ and co-workers reported that the addition of varied metal ions during the hydrothermal treatment of $p$-phenylenediamine led to the formation of fluorescent $C$-dots with emission wavelengths up to $700 \mathrm{~nm}$ [75]. Strikingly, although metal ions played a crucial role in the synthesis of C-dots with varied quantum yields, they were absent in the formed C-dots; that is, the obtained C-dots were metal-free, and the metal ions played a role similar to a "catalyst" during the C-dots formation. In light of these reports, it might be possible that a similar process has happened in our synthesis; that is, the doping element "boron" played a similar role as a "catalyst" during the formation of C-dots. As a result, we barely observed any boron in the C-dots formed, although boron was meant to be the doping element. Furthermore, we attribute the nitrogen (5.1\%) observed in our XPS characterization to the contribution of the solvent we used. Although our synthesis agents (citric acid and 1,2-diboranyethane) do not contain any nitrogen, the solvent (dimethylformamide, DMF) we used contains a fairly high percentage of nitrogen (about 19.2\%), and DMF was used in an excess amount (20 $\mathrm{mL}$ of DMF was used with only $1 \mathrm{~g}$ of citric acid and $0.3 \mathrm{~g}$ of 1,2-diboranyethane). The phenomena in which solvents took part in the formation of C-dots have been frequently reported in the literature recently. For example, in the investigations of polyethylene glycol (PEG)-assisted synthesis of metal NPs, Feldmann and co-workers frequently observed relatively intense emissions of blue light in their products that were hard to explain [76]. The unexpected fluorescence was later on attributed to C-dots formed from the thermal decomposition of solvent PEGs during metal NPs synthesis [77].

Figure 2C shows stackplots for the O 1s, N 1s, and C 1s core levels of "B-doped" C-dots scanned. The $\mathrm{C} 1 \mathrm{~s}$ oxidation state at $286.8 \mathrm{eV}$ is consistent with a $\mathrm{C}-\mathrm{O}-\mathrm{H}$ bond within the sample surface [71]. 
The $\mathrm{O} 1 \mathrm{~s}$ oxidation state at $530.9 \mathrm{eV}$ is indicative of $\mathrm{C}-\mathrm{O}$ and $\mathrm{C}-\mathrm{N}$ bonded groups to the C-dots, which is also observed by Kumar et al. [78]. The binding energy peak center at $399.3 \mathrm{eV}$, which is observed in this sample, is indicative of the presence of amine $\left(-\mathrm{NH}_{2}\right)$ groups [79]. Based on the relative, deconvoluted peak area ratios of the $\mathrm{C} 1 \mathrm{~s}$ level, the percentages of $\mathrm{C}=\mathrm{C}$ and $\mathrm{C}-\mathrm{O} / \mathrm{C}-\mathrm{N}$ carbon are $74.7 \%$ and $25.3 \%$, respectively. In summary, the spectroscopic characterizations indicate a rich presence of surface functionalities such as hydroxyl and carboxyl groups. Further, the zeta potential shows that the "B-doped" C-dots are slightly negatively charged with a value of -11.6 , which corresponds well with the spectroscopic study of the surface functionalities. The negative zeta potential value also partially explains the good dispersibility of C-dots observed in the microscopic studies discussed above.
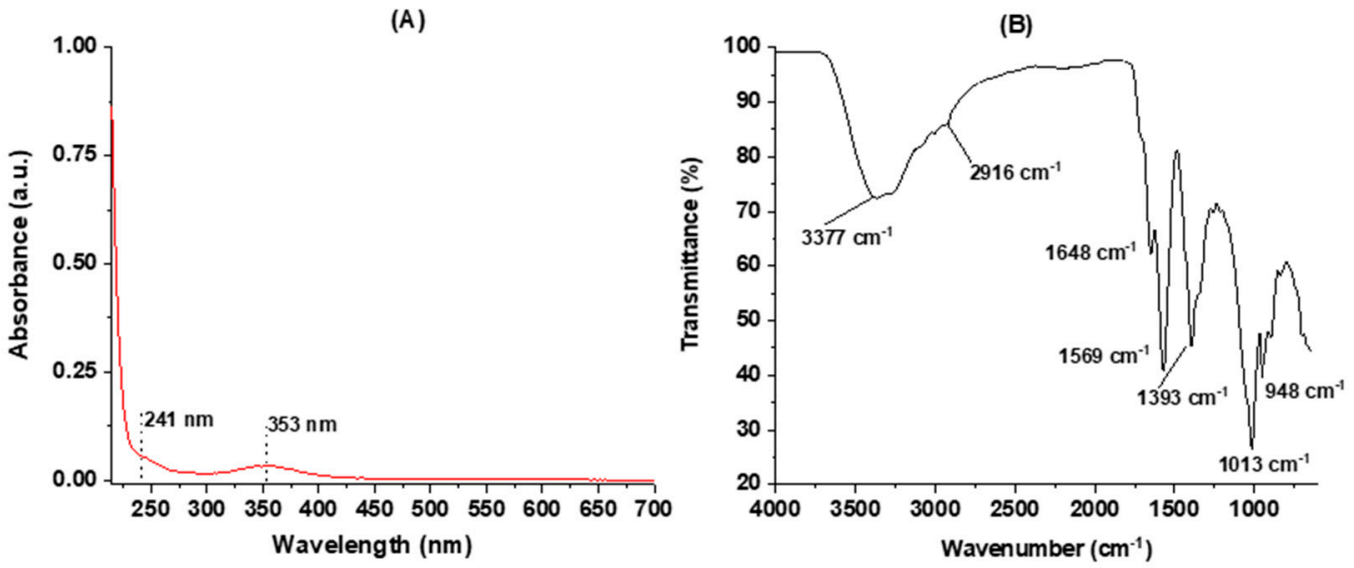

(C)
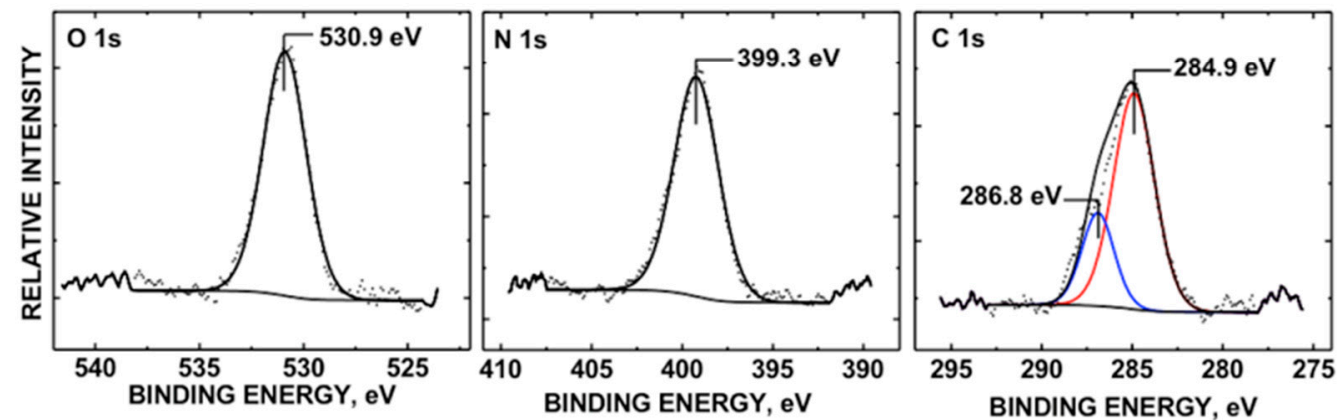

Figure 2. Spectroscopic characterization of the "B-doped" C-dots: (A) UV-Vis absorption spectrum of C-dots; (B) Fourier-transform infrared (FTIR) spectrum of C-dots with air as background; (C) XPS core levels of $\mathrm{O} 1 \mathrm{~s}, \mathrm{~N} 1 \mathrm{~s}$, and $\mathrm{C} 1 \mathrm{~s}$ orbitals of $\mathrm{C}$-dots.

Next, we investigated the PL behavior of the obtained C-dots. Excitation-wavelength-dependent PL emission is among the most notable characteristics of C-dots. As seen from the fluorescence emission spectrum (supporting information, Figure S3a), the as-prepared C-dots do demonstrate such behavior with the maximum emission at $450 \mathrm{~nm}$ when excited at $360 \mathrm{~nm}$. The excitation-wavelength-dependent PL behavior is more obvious when the emission spectrum is normalized. When excited between 280 and $380 \mathrm{~nm}$, the emissions stay around $450 \mathrm{~nm}$, while the emission spectra gradually red shift as the excitation wavelengths increase. The emission peak eventually shifts to $550 \mathrm{~nm}$ when excited at $500 \mathrm{~nm}$ (Figure 3a). As can be seen, the PL behavior of the "B-doped" C-dots is similar to the typical optical properties often observed from citric acid-based C-dots prepared from the bottom-up approach [80,81]. The PL of this type of C-dots could be explained by mainly two mechanisms, namely molecular state and carbon core state [44]. The typical absorption peaks at 340-350 nm and their corresponding emissions around $450 \mathrm{~nm}$ often observed in those citric acid-based bottom-up C-dots are believed to be related to the fluorescent molecular species (i.e., citrazinic acid type derivatives), 
which are generated together with the formation of C-dots [82-84]. The carbon core state, on the other hand, is related to the aromatic domains formed after extended heating or reaction duration, in which the molecular fluorophores likely act as the seeds for the formation of aromatic domains [73]. Since molecular fluorophores could be trapped inside C-dots or physically absorbed on the surface of C-dots, purification techniques (i.e., dialysis or size-exclusion chromatography) that could reduce the contents of molecular fluorophores on the C-dots might help reduce the complexity of the C-dots' optical properties [80].

Next, we investigated the effects of $\mathrm{pH}$ on the PL property of the C-dots. Encouragingly, our C-dots were found to be stable in both acidic and basic conditions (pH: 3.5 to 10.3), with the emission wavelengths essentially unmoved. In strong acidic $(\mathrm{pH}=2.0)$ or basic $(\mathrm{pH}=12.0)$ conditions, wavelengths of the emission were slightly shifted; however, intensities were significantly decreased (Figure $3 \mathrm{~b}$ ). The relatively high $\mathrm{pH}$ stability of our C-dots is in contrast to some C-dots that are highly $\mathrm{pH}$-sensitive [85-87], and this property endows our C-dots with the ability to adapt to different water environments (i.e., different $\mathrm{pH}$ ) as photocatalysts. Photostability is an important factor to consider when molecular fluorophores or nanomaterials are applied for photocatalysis, bioimaging, and optoelectronics; thus, we also studied the PL stability of the "B-doped" C-dots under ambient light. As can be seen, the PL emission intensity of C-dots stays essentially the same after 3 months (Supporting Information, Figure S3b), demonstrating the high stability of the as-synthesized C-dots. In addition, according to Equation (1) presented in Section 2.4, the fluorescence quantum yield of our C-dots, using quinine sulfate dissolved in $0.1 \mathrm{M} \mathrm{H}_{2} \mathrm{SO}_{4}$ as the standard, was determined to be $11 \%$. Last, according to the cell viability test, the "B-doped" C-dots demonstrated no observable cytotoxicity even when used in high concentrations (Supporting Information, Figure S4). Collectively considering these excellent properties, "B-doped" C-dots could be excellent materials for environment-related (i.e., photocatalytic dye degradation) applications.

(A)

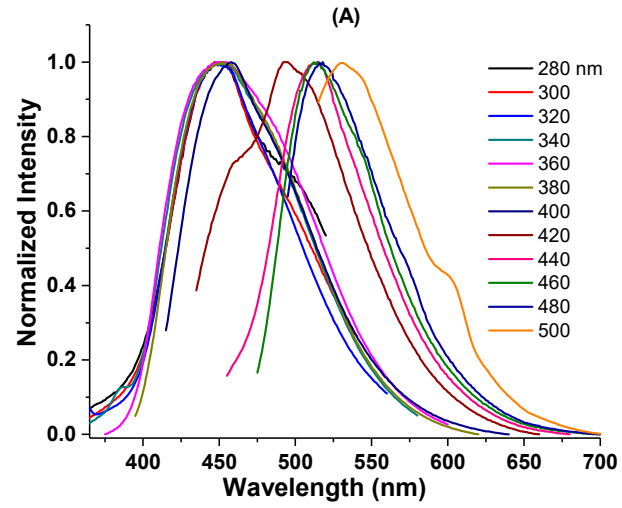

(B)

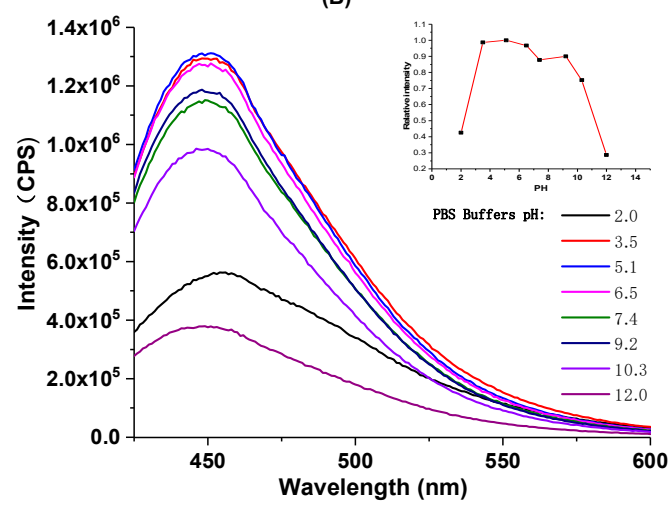

Figure 3. (A) Normalized emission spectra of C-dots; (B) fluorescence emission spectra of C-dots excited at $360 \mathrm{~nm}$ under different $\mathrm{pH}$ conditions (the inset shows the relative fluorescence intensity of C-dots excited at $360 \mathrm{~nm}$ under different $\mathrm{pH}$ ).

To evaluate the photocatalytic activity of the "B-doped" C-dots, two organic dyes, namely RhB and $\mathrm{MB}$ were selected. There are mainly two reasons to select these two dyes. First, the degradation of these two dyes has been widely used as model reactions to probe the photocatalytic ability of various materials including metal and oxide nanoparticles, quantum dots, and carbon-based nanomaterials [88-90]. Second, these two dyes are both positively charged, while our C-dots have a negative zeta potential (-11.6). As a result, the photocatalytic property of C-dots was evaluated by the degradation of $\mathrm{RhB}$ and $\mathrm{MB}$ in the presence of $0.75 \mathrm{mg} / \mathrm{mL}$ of $\mathrm{C}$-dots under simulated sunlight. As can be seen, the C-dots demonstrated excellent photocatalytic ability; both RhB and MB were quickly degraded with light irradiation, as monitored by the UV-Vis absorption spectra of the two dyes (Figure 4A1,B1). The dye 
degradation efficiency (or degree of degradation) could be reflected by the UV-Vis absorption changes of the dyes and calculated according to the following equation:

$$
D=\frac{A_{0}-A}{A_{0}} \times 100 \%
$$

where $A_{0}$ represents the absorbance of dye at time zero, and $A$ is the absorbance of dye after degradation. According to Equation (2), the degradation efficiency (\%) of RhB and MB in the presence of $\mathrm{C}$-dots versus irradiation time was plotted (Figure 4A2,B2). As presented, C-dots exhibited substantial photocatalytic activity in the degradation of both RhB and MB: within $60 \mathrm{~min}, \mathrm{RhB}$ and MB degraded (as observed by dye absorption peaks at 554 and $605 \mathrm{~nm}$, respectively) $46 \%$ and $76 \%$, respectively, while the two dyes degraded only $28 \%$ and $60 \%$ without the presence of C-dots, respectively (Supporting Information, Figure S5). Thus, the degradation efficiency of $\mathrm{RhB}$ and $\mathrm{MB}$ are increased $64 \%$ and $27 \%$, respectively, in the presence of "B-doped" C-dots as photocatalysts. Furthermore, both RhB and MB degraded completely within $170 \mathrm{~min}$.

According to the Langmuir-Hinshelwood dynamic model [91], the degradation kinetics of organic dyes (i.e., RhB and $\mathrm{MB}$ ) could be simplified according to the pseudo first-order kinetic equation below if the dye solution is very dilute:

$$
\ln \frac{A_{0}}{A}=k t
$$

where $A_{0}$ and $A$ should be the equilibrium concentration of dye adsorption and the concentration of dye after irradiation time $t$, respectively. For calculation purposes, here, $A_{0}$ and $A$ are taken as the absorbance of the dyes at time zero and the absorbance of the dyes after degradation time $t$, respectively; $\mathrm{k}$ stands for the dye degradation rate constant. According to Equation (3), the pseudo first-order degradations of RhB and MB were plotted (Figure 4A3,B3). As can be seen, both the photocatalytic degradations of $\mathrm{RhB}$ and $\mathrm{MB}$ are fitted very well with the pseudo first-order kinetics. The degradation rate constants of $\mathrm{RhB}$ and $\mathrm{MB}$ are determined to be $1.8 \times 10^{-2} \mathrm{~min}^{-1}$ and $2.4 \times 10^{-2} \mathrm{~min}^{-1}$, respectively. It's worth mentioning that the degradation efficiency and rate constant of $\mathrm{MB}$ as monitored by the absorbance at $664 \mathrm{~nm}$ were also calculated, which are, as expected, very similar to those determined by using the absorbance at $605 \mathrm{~nm}$ (Supporting Information, Figure S6).

As such, our C-dots exhibited excellent photocatalytic activity compared to most of the bare C-dots previously reported (Table 1). Most of the C-dots previously synthesized have shown little photocatalytic activity toward dye degradation (Table 1, entries 1-4) [48-52]; in order to catalyze the degradation of organic dyes efficiently, they have to composite with metal-based nanoparticles (Table 1, entries 2-4) [50-57], which not only significantly complicated the preparation procedures and reduced yields, but also increased cost and environmental concerns. For example, Yu et al. reported C-dots/TNS and C-dots/P25 composites with excellent photocatalytic activity for the degradation of $\mathrm{RhB}$; however, there was no activity when C-dots were used alone [52]. Recently, some encouraging studies have shown that $\mathrm{C}$-dots alone could possess good to excellent photocatalytic activity toward the degradation of organic dyes (Table 1, entries 5-10); however, various factors including limited light absorption, extra surface doping, as well as tedious separation have limited the practical applications of C-dots in these studies [58-63]. For instance, C-dots prepared by Srivastava and co-workers could only utilize light with a specific wavelength for the catalytic degradation of MB [59]. In the report by Kang and co-workers, nitrogen doping is required in order to improve the photocatalytic activity; bare C-dots exhibited very low efficiency, with only $30 \%$ of methylene orange degradation after $120 \mathrm{~min}$ irradiation [60]. In a recent study by Leblanc and co-workers, only one fraction of their as-prepared C-dots demonstrated excellent photocatalytic activity toward the degradation of RhB and $\mathrm{MB}$, which had to be separated through a tedious size exclusion chromatography [63]. Considering the excellent photocatalytic efficiency toward the degradation of $\mathrm{RhB}$ and $\mathrm{MB}$, as well as the fact that they are facilely synthesized with no need of further doping, compositing, and tedious purification 
and separation, C-dots prepared in this work are shown to be a very promising alternative for dye degradation and environment cleanliness (Table 1, entry 11).
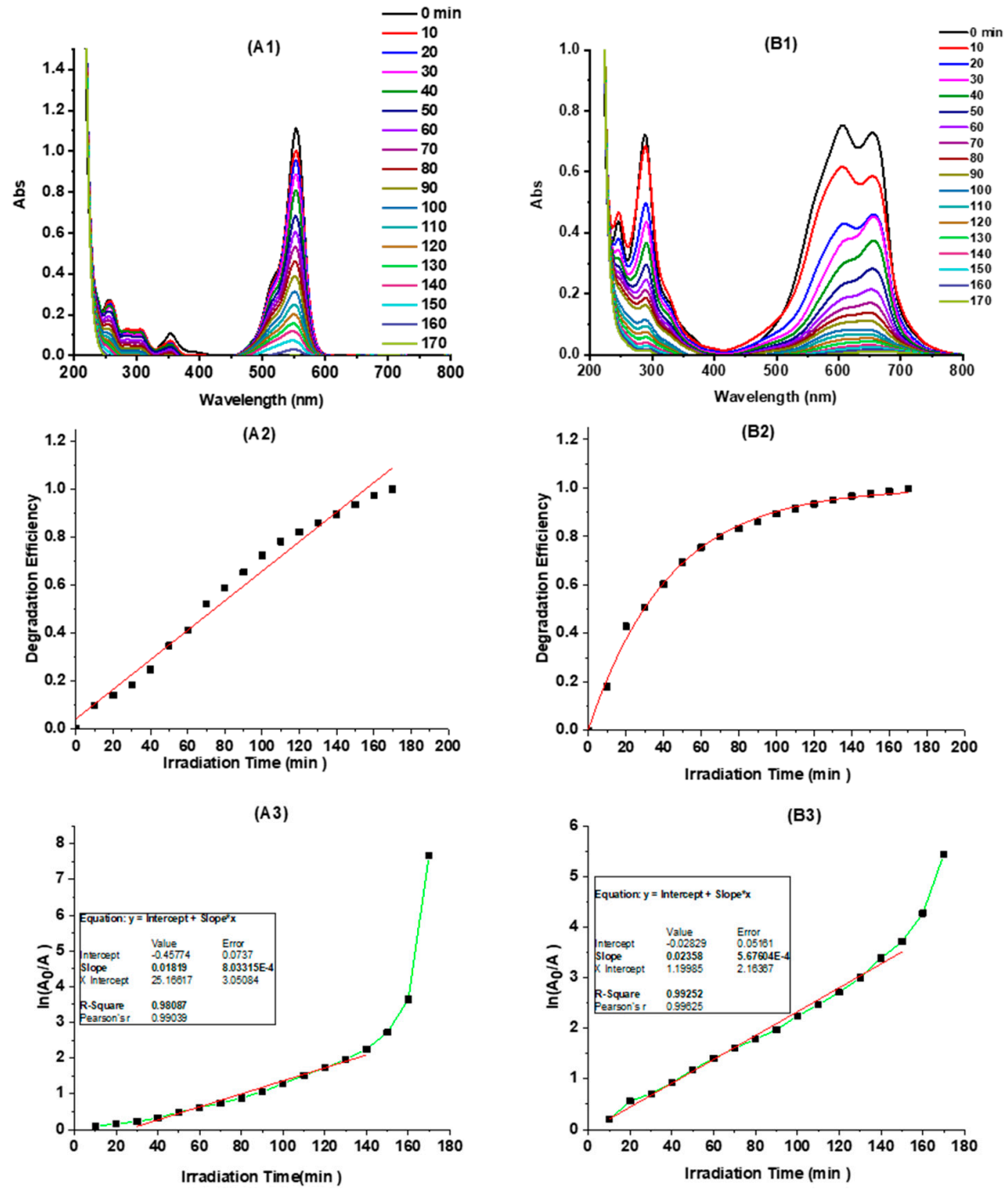

Figure 4. The photocatalytic degradation of rhodamine $B(\mathrm{RhB})$ and methylene blue $(\mathrm{MB})$ catalyzed by C-dots $(0.75 \mathrm{mg} / \mathrm{mL})$ : the UV-Vis absorption spectra of RhB (A1) and MB (B1) at different irradiation times; the degradation efficiency (\%) of $\mathrm{RhB}(\mathrm{A} 2)$ and $\mathrm{MB}$ (B2) by monitoring the absorption changes at $554 \mathrm{~nm}$ and $605 \mathrm{~nm}$, respectively, at different irradiation times; irradiation-time-dependent pseudo first-order kinetics plots $\left(\ln \left(A_{0} / A\right)\right.$ vs. irradiation time) of $\operatorname{RhB}(\mathbf{A} 3)$ and $\mathrm{MB}(\mathrm{B} 3)$.

According to the results and discussions above, a plausible photocatalytic mechanism for dye degradation under the catalysis of "B-doped" C-dots is proposed (Figure 5). When photons of appropriate energy excite $\mathrm{C}$-dots, electrons were excited from the ground state (valence band) to excitation state (conduction band), generating excess electrons $\left(\mathrm{e}^{-}\right)$and holes $\left(\mathrm{h}^{+}\right)$. Due to the rich presence of surface defects (i.e., surface functionalities) on C-dots, some of the excited carriers are trapped, and the recombination of $\mathrm{e}^{-}$and $\mathrm{h}^{+}$are hindered. As a result, the organic dyes could be oxidized by the $\mathrm{h}^{+}$directly to cause the degradation, which is well known [62]. In the meantime, some of the $\mathrm{e}^{-}$could be captured by oxygen dissolved in solution, forming super oxide radicals (i.e., $\bullet \mathrm{O}_{2}{ }^{-}$); some of the $\mathrm{h}^{+}$could interact with surface-adsorbed $\mathrm{H}_{2} \mathrm{O}$ to form hydroxyl radicals (i.e., $\bullet \mathrm{OH}$ ). Reactive oxygen species (ROS) such as super oxide $\bullet \mathrm{O}_{2}{ }^{-}$[63] and hydroxyl radical $\bullet \mathrm{OH}[62,92]$ are known to degrade organic dyes. 
Table 1. Comparison of the photo degradation performance of different C-dots-related catalysts.

\begin{tabular}{|c|c|c|c|c|c|}
\hline Entry & Material $^{c}$ & Dye ${ }^{d}$ & Degradation Efficiency & Rate Constant $\left(\min ^{-1}\right)$ & Reference \\
\hline 1 & C-dots & MB & $90 \% / 1800 \mathrm{~min} ; 85 \% / 120 \mathrm{~min}$ & $2.7 \times 10^{-3} 1.4 \times 10^{-2}$ & {$[48,49]$} \\
\hline \multirow{2}{*}{2} & C-dots/ZnPor & \multirow{2}{*}{ MB } & $95 \% / 60 \mathrm{~min}$ & \multirow[t]{2}{*}{-} & \multirow{2}{*}[50]{} \\
\hline & C-dots only & & $4 \% / 60 \mathrm{~min}$ & & \\
\hline \multirow{2}{*}{3} & C-dots $/ \mathrm{TiO}_{2}$ & \multirow{2}{*}{ RhB } & $95 \% / 30 \mathrm{~min}$ & $1.1 \times 10^{-1}$ & \multirow{2}{*}{ [51] } \\
\hline & C-dots only & & $0 \% / 30 \mathrm{~min}$ & $5.1 \times 10^{-4}$ & \\
\hline \multirow{2}{*}{4} & C-dots/TNS & \multirow{2}{*}{$\mathrm{RhB}$} & $95 \% / 60 \mathrm{~min}$ & \multirow[t]{2}{*}{-} & \multirow{2}{*}{ [52] } \\
\hline & C-dots only & & $0 \% / 60 \mathrm{~min}$ & & \\
\hline 5 & C-dots & RhB & $97 \% / 240 \mathrm{~min}$ & $2.5 \times 10^{-2}$ & [58] \\
\hline $6^{\mathrm{a}}$ & C-dots & MB & $80 \% / 60 \mathrm{~min}$ & $2.4 \times 10^{-2}$ & [59] \\
\hline $7^{b}$ & C-dots & $\mathrm{MO}$ & $90 \% / 120 \mathrm{~min}$ & - & [60] \\
\hline 8 & C-dots & MB & $96 \% / 90 \mathrm{~min}$ & $3.1 \times 10^{-2}$ & [61] \\
\hline 9 & C-dots & MB & $99.5 \% / 130 \mathrm{~min}$ & $3.9 \times 10^{-2}$ & [62] \\
\hline \multirow{2}{*}{10} & \multirow{2}{*}{ C-dots } & $\mathrm{RhB}$ & $50 \% / 60 \mathrm{~min}$ & $1.3 \times 10^{-2}$ & \multirow{2}{*}{ [63] } \\
\hline & & MB & $90 \% / 60 \mathrm{~min}$ & $3.6 \times 10^{-2}$ & \\
\hline \multirow{2}{*}{11} & \multirow{2}{*}{ C-dots } & $\mathrm{RhB}$ & $99.9 \% / 170 \mathrm{~min}$ & $1.8 \times 10^{-2}$ & \multirow{2}{*}{ This work } \\
\hline & & MB & $99.9 \% / 170 \mathrm{~min}$ & $2.4 \times 10^{-2}$ & \\
\hline
\end{tabular}

${ }^{a}$ Single-wavelength light, instead of sunlight, was used for catalytic degradation. ${ }^{\mathrm{b}}$ Data shown for N-doped C-dots; C-dots without doping: only $31.5 \%$ dyes were degraded within $120 \mathrm{~min} .{ }^{\mathrm{C}} \mathrm{C}$-dots/ZnPor: nanocomposite of zinc porphyrin functionalized graphene quantum dots; C-dots/TNS: nanocomposites of C-dots and $\mathrm{TiO}_{2}$ nanosheets. d MB: methylene blue; RhB: rhodamine B; MO: methylene orange.

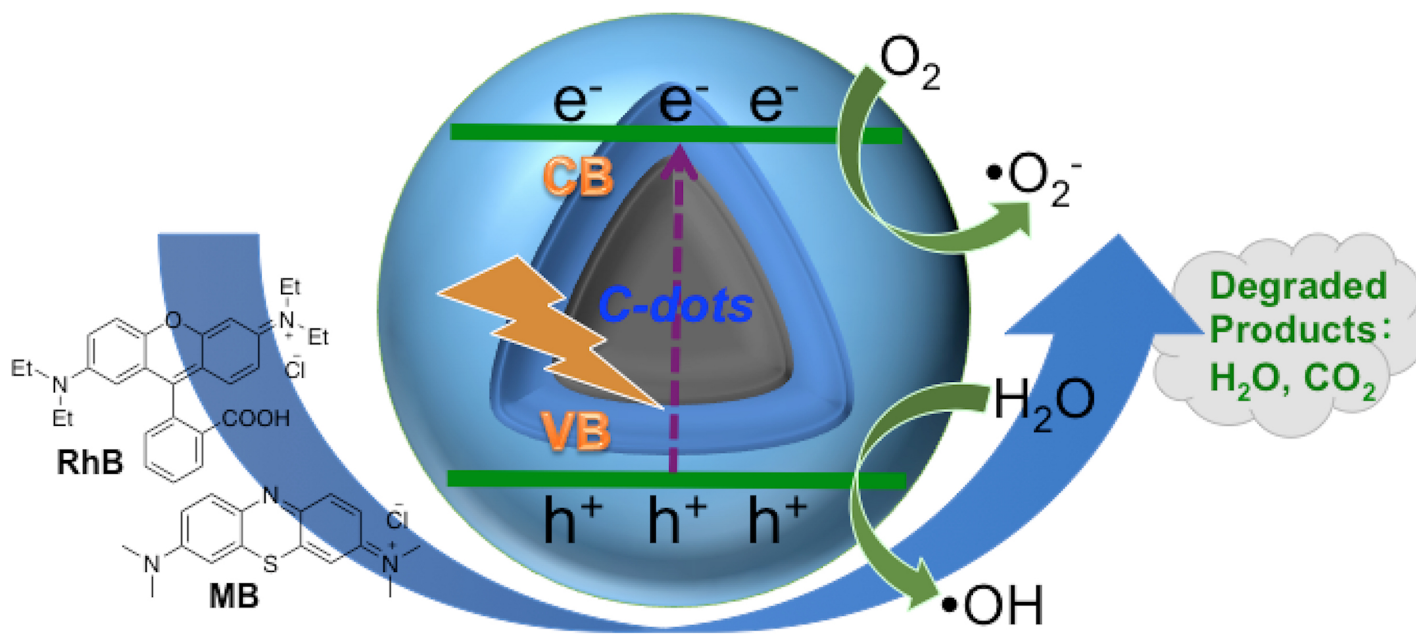

\section{Efficient Dye Degradation}

Figure 5. A plausible mechanism of the photocatalytic degradation of RhB and MB catalyzed by "B-doped" C-dots.

\section{Conclusions}

The significant potential of C-dots as highly efficient photocatalysts for organic dye degradation in water remediation was explored. The visible-light-sensitive C-dots were synthesized through a facile hydrothermal method from CA and DBE, and they could be readily purified by simple dialysis. The nontoxic C-dots demonstrate typical excitation-wavelength-dependent emission with high photostability. Under visible light irradiation, the C-dots present excellent photocatalytic activity, achieving $100 \%$ of $\mathrm{RhB}$ and $\mathrm{MB}$ degradation within $170 \mathrm{~min}$. The degradation of $\mathrm{RhB}$ and $\mathrm{MB}$ were well fitted with the pseudo first-order kinetics and the degradation rate constants for $\mathrm{RhB}$ and $\mathrm{MB}$ were 
$1.8 \times 10^{-2} \mathrm{~min}^{-1}$ and $2.4 \times 10^{-2} \mathrm{~min}^{-1}$, respectively. The photocatalytic degradation performances are comparable to those metal-based photocatalysts and generally better than previously reported C-dots photocatalysts. Collectively considering their excellent photocatalytic activity toward the organic dye degradation, as well as the fact that they are facilely synthesized with no need of further doping, compositing, and tedious purification and separation, C-dots fabricated in this work are shown to be a promising alternative for pollutant degradation and environment protection.

Supplementary Materials: The following are available online at http://www.mdpi.com/2079-4991/10/8/1560/s1, Figure S1: Spectrum of high power Mercury-Xenon $\mathrm{Hg}(\mathrm{Xe})$ lamps used in this study. Figure S2: Schematic illustration of C-dots synthesis. Figure S3: Fluorescence emission spectra of C-dots excited at different wavelengths; and relative fluorescence intensity of $\mathrm{C}$-dots exposed to ambient light with different time durations. Figure S4: Cell viability test of C-dots using MTS assay. Figure S5: The photo-degradation of RhB and MB without the presence of photocatalysts. Figure S6: The photocatalytic degradation of MB catalyzed by C-dots $(0.75 \mathrm{mg} / \mathrm{mL})$ by monitoring the absorption at $664 \mathrm{~nm}$. Table S1: Table showing the XPS elemental atom \% and BEs of O $1 \mathrm{~s}, \mathrm{~N} 1 \mathrm{~s}$ and $\mathrm{C} 1 \mathrm{~s}$ core levels.

Author Contributions: Conceptualization, Z.P. and R.M.L.; Data curation, Z.P., J.P., K.J.M., R.R.P., C.C.C. and R.M.G.; Formal analysis, Z.P., Y.Z., C.J., J.P., C.C.C., R.M.G. and R.L.; Funding acquisition, Z.P., G.Y. and R.M.L.; Investigation, Y.Z.; Methodology, Z.P. and Y.Z.; Project administration, Z.P. and G.Y.; Validation, C.J.; Writing-original draft, Z.P.; Writing—review and editing, Z.P., Y.Z., C.J., K.J.M., G.Y. and R.M.L. All authors have read and agreed to the published version of the manuscript.

Funding: Z. Peng and C. Ji gratefully acknowledge the financial support from the National Natural Science Foundation of China (grant number: 21807010) and the Applied Basic Research Program of Yunnan Province (grant number: 2019FB066). Y. Zhou, K. Mintz and R. M. Leblanc gratefully acknowledge the support of the National Science Foundation under Grant 2041413. Z. Peng and G. Yan thank the support from the Open Project of Key Laboratory of Green Energy and Environment Catalysis (Ningde Normal University), Fujian Province University, Ningde, 352100, People's Republic of China (No. FJ-GEEC201902).

Conflicts of Interest: The authors declare no conflict of interest.

\section{References}

1. Chequer, F.F.D.; de Oliveira, G.A.R.; Ferraz, E.R.A.; Cardoso, J.C.; Zanoni, M.B.; de Oliveira, D.P. Textile dyes: Dyeing process and environmental impact. In Eco-Friendly Textile Dyeing and Finishing; Günay, M., Ed.; IntechOpen: London, UK, 2013; pp. 151-176.

2. Long, Y.; Li, L.; Zhou, L.; Zhang, S.; Wang, L.; Zheng, Z.; Wu, S.; Hei, Y.; Jiang, F. Fabrication of the $\mathrm{AgI} / \mathrm{BiOI} / \mathrm{BiPO}_{4}$ multi-heterojunction with high photocatalytic activity. Mater. Res. Bull. 2020, 126, 110787. [CrossRef]

3. Wang, S.; Chen, Y.; Li, L.; Long, Y.; Shi, Y.; Zhang, Y.; Jiang, F. Preparation and characterization of $\mathrm{CdS} / \mathrm{BiOI}$ composites with enhanced photocatalytic activity for degradation of 17 alpha-ethinyl estradiol. Mater. Res. Bull. 2018, 99, 444-452. [CrossRef]

4. Ajmal, A.; Majeed, I.; Malik, R.N.; Idriss, H.; Nadeem, M.A. Principles and mechanisms of photocatalytic dye degradation on $\mathrm{TiO}_{2}$ based photocatalysts: A comparative overview. RSC Adv. 2014, 4, 37003-37026. [CrossRef]

5. Fujishima, F.; Honda, K. Electrochemical photolysis of water at a semiconductor electrode. Nature 1972, 238, 37-38. [CrossRef]

6. Carey, J.H.; Lawrence, J.; Tosine, H.M. Photodechlorination of PCB's in the presence of titanium dioxide in aqueous suspensions. Bull. Environ. Contam. Toxicol. 1976, 16, 697-701. [CrossRef]

7. Lv, T.; Zhao, J.; Chen, M.; Shen, K.; Zhang, D.; Zhang, J.; Zhang, G.; Liu, Q. Boosted visible-light photodegradation of methylene blue by $\mathrm{V}$ and $\mathrm{Co}$ co-doped $\mathrm{TiO}_{2}$. Materials 2018, 11, 1946. [CrossRef]

8. Yang, Y.; Luo, L.; Xiao, M.; Li, H.; Pan, X.; Jiang, F. One-step hydrothermal synthesis of surface fluorinated $\mathrm{TiO}_{2} /$ reduced graphene oxide nanocomposites for photocatalytic degradation of estrogens. Mater. Sci. Semicond. Process. 2015, 40, 183-193. [CrossRef]

9. Zhang, Y.; Zhang, J.; Zhu, Z.; Yan, N.; Liu, Q. Preparation and properties of sliver and nitrogen co-doped $\mathrm{TiO}_{2}$ photocatalyst. Mater. Res. Bull. 2013, 48, 4872-4876. [CrossRef]

10. Yan, N.; Zhu, Z.; Zhang, J.; Zhao, Z.; Liu, Q. Preparation and properties of ce-doped $\mathrm{TiO}_{2}$ photocatalyst. Mater. Res. Bull. 2012, 47, 1869-1873. [CrossRef] 
11. Wu, J.; Liu, Q.; Gao, P.; Zhu, Z. Influence of praseodymium and nitrogen co-doping on the photocatalytic activity of $\mathrm{TiO}_{2}$. Mater. Res. Bull. 2011, 46, 1997-2003. [CrossRef]

12. Han, F.; Kambala, V.S.R.; Srinivasan, M.; Rajarathnam, D.; Naidu, R. Tailored titanium dioxide photocatalysts for the degradation of organic dyes in wastewater treatment: A review. Appl. Catal. A Gen. 2009, 359, $25-40$. [CrossRef]

13. Xing, X.; Deng, D.; Li, Y.; Chen, N.; Liu, X.; Wang, Y. Macro-/nanoporous Al-doped ZnO via self-sustained decomposition of metal-organic complexes for application in degradation of Congo red. Ceram. Int. 2016, 42, 18914-18924. [CrossRef]

14. Lee, K.M.; Lai, C.W.; Ngai, K.S.; Juan, J.C. Recent developments of zinc oxide based photocatalyst in water treatment technology: A review. Water Res. 2011, 88, 428-448.

15. Dong, C.; Xiao, X.; Chen, G.; Guan, H.; Wang, Y. Synthesis and photocatalytic degradation of methylene blue over p-n junction $\mathrm{Co}_{3} \mathrm{O}_{4} / \mathrm{ZnO}$ core/shell nanorods. Mater. Chem. Phys. 2015, 155, 1-8. [CrossRef]

16. Zhang, J.; Deng, S.J.; Liu, S.Y.; Chen, J.M.; Han, B.Q.; Wang, Y.; Wang, Y.D. Preparation and photocatalytic activity of $\mathrm{Nd}$ doped $\mathrm{ZnO}$ nanoparticles. Mater. Technol. 2014, 29, 262-268. [CrossRef]

17. Huang, D.; Long, Y.; Luo, L.; Li, L.; Zhang, S.; Wang, L.; Jiang, F. Synthesis of N-doped $\mathrm{Bi}_{2} \mathrm{O}_{3}$ and Its excellent visible light photocatalytic performance for the degradation of 17 beta-Estradiol. Sci. Adv. Mater. 2019, 11, 105-111. [CrossRef]

18. Shi, Y.; Luo, L.; Zhang, Y.; Chen, Y.; Wang, S.; Li, L.; Long, Y.; Jiang, F. Synthesis and characterization of porous platelet-shaped alpha- $\mathrm{Bi}_{2} \mathrm{O}_{3}$ with enhanced photocatalytic activity for 17 alpha-ethynylestradiol. J. Mater. Sci. 2018, 53, 1049-1064. [CrossRef]

19. Chen, Y.; Zhang, Y.; Luo, L.; Shi, Y.; Wang, S.; Li, L.; Long, Y.; Jiang, F. A novel templated synthesis of $\mathrm{C} / \mathrm{N}$-doped $\beta-\mathrm{Bi}_{2} \mathrm{O}_{3}$ nanosheets for synergistic rapid removal of $17 \alpha$-ethynylestradiol by adsorption and photocatalytic degradation. Ceram. Int. 2018, 44, 2178-2185. [CrossRef]

20. Xie, Z.; Zhou, Y.; Guan, L.; Muhammad, S.; Jiang, Y.; Zhang, S.; Yu, C.; Jiao, Y.; Zhang, S.; Ren, Y.; et al. Effect of impurity in $\mathrm{Cu}_{2} \mathrm{O}$ nanowires on the degradation of methyl orange. J. Mater. Sci. Mater. Electron. 2020, 31, 3817-3824. [CrossRef]

21. Yu, C.; Shu, Y.; Zhou, X.; Ren, Y.; Liu, Z. Multi-branched $\mathrm{Cu}_{2} \mathrm{O}$ nanowires for photocatalytic degradation of methyl orange. Mater. Res. Express 2018, 5. [CrossRef]

22. Zhang, D.; Chen, M.; Zou, H.; Zhang, Y.; Hu, J.; Wang, H.; Zi, B.; Zhang, J.; Zhu, Z.; Duan, L.; et al. Microwave-assisted synthesis of porous and hollow alpha- $\mathrm{Fe}_{2} \mathrm{O}_{3} / \mathrm{LaFeO}_{3}$ nanostructures for acetone gas sensing as well as photocatalytic degradation of methylene blue. Nanotechnology 2020, 31. [CrossRef]

23. Zhang, F.; Liu, Y.J.; Xiao, X.C.; Cai, X.Y.; Li, H.; Wang, Y.D. Synthesis and characterisation of highly ordered mesoporous $\mathrm{Fe}_{2} \mathrm{O}_{3}-\mathrm{SiO}_{2}$ composite and its removal properties of azo dyes from aqueous solution. Mater. Technol. 2012, 27, 196-204. [CrossRef]

24. Cai, X.; Cai, Y.; Liu, Y.; Deng, S.; Wang, Y.; Wang, Y.; Djerdj, I. Photocatalytic degradation properties of $\mathrm{Ni}(\mathrm{OH})_{2}$ nanosheets/ZnO nanorods composites for azo dyes under visible-light irradiation. Ceram. Int. 2014, 40, 57-65. [CrossRef]

25. Zhang, F.; Liu, Y.J.; Liu, Q.H.; Li, Q.; Li, H.; Cai, X.Y.; Wang, Y.D. Synthesis and characterisation of $\mathrm{Ni}(\mathrm{OH})_{2}$ and $\mathrm{NiO}$ nanosheets and their removal properties of azo dyes from aqueous solution. Mater. Technol. 2013, 28, 310-315. [CrossRef]

26. Wang, Y.; Liu, S.; Cai, Y.; Deng, S.; Han, B.; Han, R.; Li, Q.; Wang, Y. $\mathrm{La}(\mathrm{OH})_{3}: \mathrm{Ln}^{3+}(\mathrm{Ln}=\mathrm{Sm}, \mathrm{Er}, \mathrm{Gd}$, $\mathrm{Dy}$, and $\mathrm{Eu}$ ) nanorods synthesized by a facile hydrothermal method and their enhanced photocatalytic degradation of Congo red in the aqueous solution. Ceram. Int. 2014, 40, 5091-5095. [CrossRef]

27. Wang, J.; Ou, E.; Li, J.; Yang, X.; Wang, W.; Yan, Z.; Li, C. Synthesis of mesoporous titania-graphite composite templated by hypocrellins for visible-light photocatalytic degradation of acetaldehyde. Mater. Sci. Semicond. Process. 2015, 31, 397-404. [CrossRef]

28. Tao, J.; Gong, W.; Yan, Z.; Duan, D.; Zeng, Y.; Wang, J. UV/visible-light photodegradation of organic dyes over mesoporous titania prepared by using 2,4,5-triphenylimidazole as template. Mater. Sci. Semicond. Process. 2014, 27, 452-460. [CrossRef]

29. Han, B.; Zhang, F.; Feng, Z.; Liu, S.; Deng, S.; Wang, Y.; Wang, Y. A designed $\mathrm{Mn}_{2} \mathrm{O}_{3} / \mathrm{MCM}^{-41}$ nanoporous composite for methylene blue and rhodamine B removal with high efficiency. Ceram. Int. 2014, 40, 8093-8101. [CrossRef] 
30. Li, C.; Wang, J.; Feng, S.; Yang, Z.; Ding, S. Low-temperature synthesis of heterogeneous crystalline $\mathrm{TiO}_{2}$-halloysite nanotubes and their visible light photocatalytic activity. J. Mater. Chem. A 2013, 1, 8045-8054. [CrossRef]

31. Miao, Y.; Zhai, Z.; He, J.; Li, B.; Li, J.; Wang, J. Synthesis, characterizations and photocatalytic studies of mesoporous titania prepared by using four plant skins as templates. Mater. Sci. Eng. C 2010, 30, 839-846. [CrossRef]

32. Nakata, K.; Fujishima, A. $\mathrm{TiO}_{2}$ photocatalysis: Design and applications. J. Photochem. Photobiol. C-Photochem. Rev. 2012, 13, 169-189. [CrossRef]

33. Peng, Z.; Zhao, T.; Zhou, Y.; Li, S.; Li, J.; Leblanc, R.M. Bone tissue engineering via carbon-based nanomaterials. Adv. Healthc. Mater. 2020, 9. [CrossRef] [PubMed]

34. Peng, Z.; Han, X.; Li, S.; Al-Youbi, A.O.; Bashammakh, A.S.; El-Shahawi, M.S.; Leblanc, R.M. Carbon dots: Biomacromolecule interaction, bioimaging and nanomedicine. Coord. Chem. Rev. 2017, 343, $256-277$. [CrossRef]

35. Lim, S.Y.; Shen, W.; Gao, Z.Q. Carbon quantum dots and their applications. Chem. Soc. Rev. 2015, 44, 362-381. [CrossRef] [PubMed]

36. Wang, Y.F.; Hu, A.G. Carbon quantum dots: Synthesis, properties and applications. J. Mater. Chem. C 2014, 2, 6921-6939. [CrossRef]

37. Peng, Z.; Ji, C.; Zhou, Y.; Zhao, T.; Leblanc, R.M. Polyethylene glycol (PEG) derived carbon dots: Preparation and applications. Appl. Mater. Today 2020, 20. [CrossRef]

38. Zheng, Z.; Li, H.; Zhang, X.; Jiang, H.; Geng, X.; Li, S.; Tu, H.; Cheng, X.; Yang, P.; Wan, Y. High-absorption solar steam device comprising $\mathrm{Au} @ \mathrm{Bi}_{2} \mathrm{MoO}_{6}-\mathrm{CD}$ s: Extraordinary desalination and electricity generation. Nano Energy 2020, 68. [CrossRef]

39. Zhou, Y.; Mintz, K.J.; Cheng, L.; Chen, J.; Ferreira, B.C.; Hettiarachchi, S.D.; Liyanage, P.Y.; Seven, E.S.; Miloserdov, N.; Pandey, R.R. Direct conjugation of distinct carbon dots as lego-like building blocks for the assembly of versatile drug nanocarriers. J. Colloid Interface Sci. 2020, 576, 412-425. [CrossRef]

40. Zhou, X.; Qu, Q.; Wang, L.; Li, L.; Li, S.; Xia, K. Nitrogen dozen carbon quantum dots as one dual function sensing platform for electrochemical and fluorescent detecting ascorbic acid. J. Nanopart. Res. 2020, 22, 1-13. [CrossRef]

41. Tang, J.; Zhang, J.; Shi, P.; Xiao, Y.; Shi, Y.; Ding, L.; Xu, W. Synthesis of fluorescent carbon quantum dots from tobacco wastewater for the detection of ferric(III) ions. Sci. Adv. Mater. 2020, 12, 966-972. [CrossRef]

42. Yang, Y.; Zou, T.; Wang, Z.; Xing, X.; Peng, S.; Zhao, R.; Zhang, X.; Wang, Y. The fluorescent quenching mechanism of $\mathrm{N}$ and $\mathrm{S} \mathrm{Co}$-doped graphene quantum dots with $\mathrm{Fe}^{3+}$ and $\mathrm{Hg}^{2+}$ ions and their application as a novel fluorescent sensor. Nanomaterials 2019, 9, 738. [CrossRef] [PubMed]

43. Cayuela, A.; Soriano, M.L.; Carrillo-Carrion, C.; Valcarcel, M. Semiconductor and carbon-based fluorescent nanodots: The need for consistency. Chem. Commun. 2016, 52, 1311-1326. [CrossRef] [PubMed]

44. Zhu, S.J.; Song, Y.B.; Zhao, X.H.; Shao, J.R.; Zhang, J.H.; Yang, B. The photoluminescence mechanism in carbon dots (graphene quantum dots, carbon nanodots, and polymer dots): Current state and future perspective. Nano Res. 2015, 8, 355-381. [CrossRef]

45. Yu, J.; Liu, C.; Yuan, K.; Lu, Z.; Cheng, Y.; Li, L.; Zhang, X.; Jin, P.; Meng, F.; Liu, H. Luminescence mechanism of carbon dots by tailoring functional groups for sensing $\mathrm{Fe}^{3+}$ ions. Nanomaterials 2018, 8, 233. [CrossRef] [PubMed]

46. Han, M.; Zhu, S.; Lu, S.; Song, Y.; Feng, T.; Tao, S.; Liu, J.; Yang, B. Recent progress on the photocatalysis of carbon dots: Classification, mechanism and applications. Nano Today 2018, 19, 201-218. [CrossRef]

47. Li, H.; Zheng, Z.; Liu, M.; Jiang, H.; Hu, D.; Zhang, X.; Xia, L.; Geng, X.; Lu, J.; Cheng, X. Visible light photo-treatment of simulated wastewater activated by high-efficient photocatalyst: A novel heterojunction of $\mathrm{Bi}_{2} \mathrm{MoO}_{6}$ balls and Pd nanoskeletons. Appl. Surf. Sci. 2020, 510, 145468. [CrossRef]

48. Aji, M.P.; Wiguna, P.A.; Rosita, N.; Aisyah, S. Carbon nanodots from frying oil as catalyst for photocatalytic degradation of methylene blue assisted solar light irradiation. Am. J. Appl. Sci. 2016, 13, 432-438. [CrossRef]

49. Bhati, A.; Singh, A.; Tripathi, K.M.; Sonkar, S.K. Sunlight-induced photochemical degradation of methylene blue by water-soluble carbon nanorods. Int. J. Photoenergy 2016. [CrossRef] 
50. Lu, Q.; Zhang, Y.; Liu, S. Graphene quantum dots enhanced photocatalytic activity of zinc porphyrin toward the degradation of methylene blue under visible-light irradiation. J. Mater. Chem. A 2015, 3, 8552-8558. [CrossRef]

51. Zhang, Y.-Q.; Ma, D.-K.; Zhang, Y.-G.; Chen, W.; Huang, S.-M. N-doped carbon quantum dots for TiO 2 -based photocatalysts and dye-sensitized solar cells. Nano Energy 2013, 2, 545-552. [CrossRef]

52. Yu, X.; Liu, J.; Yu, Y.; Zuo, S.; Li, B. Preparation and visible light photocatalytic activity of carbon quantum dots/ $\mathrm{TiO}_{2}$ nanosheet composites. Carbon 2014, 68, 718-724. [CrossRef]

53. Muthulingam, S.; Lee, I.-H.; Uthirakumar, P. Highly efficient degradation of dyes by carbon quantum dots/N-doped zinc oxide (CQD/N-ZnO) photocatalyst and its compatibility on three different commercial dyes under daylight. J. Colloid Interface Sci. 2015, 455, 101-109. [CrossRef] [PubMed]

54. Wang, X.; Li, L.; Fu, Z.; Cui, F. Carbon quantum dots decorated CuS nanocomposite for effective degradation of methylene blue and antibacterial performance. J. Mol. Liq. 2018, 268, 578-586. [CrossRef]

55. Sun, A.-C. Synthesis of magnetic carbon nanodots for recyclable photocatalytic degradation of organic compounds in visible light. Adv. Powder Technol. 2018, 29, 719-725. [CrossRef]

56. Safardoust-Hojaghan, H.; Salavati-Niasari, M. Degradation of methylene blue as a pollutant with N-doped graphene quantum dot/titanium dioxide nanocomposite. J. Clean. Prod. 2017, 148, 31-36. [CrossRef]

57. Atchudan, R.; Edison, T.N.J.I.; Perumal, S.; Karthik, N.; Karthikeyan, D.; Shanmugam, M.; Lee, Y.R. Concurrent synthesis of nitrogen-doped carbon dots for cell imaging and ZnO@ nitrogen-doped carbon sheets for photocatalytic degradation of methylene blue. J. Photochem. Photobiol. A Chem. 2018, 350, 75-85. [CrossRef]

58. Cheng, Y.; Bai, M.; Su, J.; Fang, C.; Li, H.; Chen, J.; Jiao, J. Synthesis of fluorescent carbon quantum dots from aqua mesophase pitch and their photocatalytic degradation activity of organic dyes. J. Mater. Sci. Technol. 2019, 35, 1515-1522. [CrossRef]

59. Umrao, S.; Sharma, P.; Bansal, A.; Sinha, R.; Singh, R.K.; Srivastava, A. Multi-layered graphene quantum dots derived photodegradation mechanism of methylene blue. RSC Adv. 2015, 5, 51790-51798. [CrossRef]

60. Ma, Z.; Ming, H.; Huang, H.; Liu, Y.; Kang, Z. One-step ultrasonic synthesis of fluorescent N-doped carbon dots from glucose and their visible-light sensitive photocatalytic ability. New J. Chem. 2012, 36, 861-864. [CrossRef]

61. Singh, A.; Khare, P.; Verma, S.; Bhati, A.; Sonker, A.K.; Tripathi, K.M.; Sonkar, S.K. Pollutant soot for pollutant dye degradation: Soluble graphene nanosheets for visible light induced photodegradation of methylene blue. ACS Sustain. Chem. Eng. 2017, 5, 8860-8869. [CrossRef]

62. Das, G.S.; Shim, J.P.; Bhatnagar, A.; Tripathi, K.M.; Kim, T. Biomass-derived carbon quantum dots for visible-light-induced photocatalysis and label-free detection of Fe (III) and ascorbic acid. Sci. Rep. 2019, 9, $1-9$.

63. Zhou, Y.; Zahran, E.M.; Quiroga, B.A.; Perez, J.; Mintz, K.J.; Peng, Z.; Liyanage, P.Y.; Pandey, R.R.; Chusuei, C.C.; Leblanc, R.M. Size-dependent photocatalytic activity of carbon dots with surface-state determined photoluminescence. Appl. Catal. B: Environ. 2019, 248, 157-166. [CrossRef]

64. Yang, P.; Zhao, J.; Zhang, L.; Li, L.; Zhu, Z. Intramolecular hydrogen bonds quench photoluminescence and enhance photocatalytic activity of carbon nanodots. Chem. Eur. J. 2015, 21, 8561-8568. [CrossRef] [PubMed]

65. Hettiarachchi, S.D.; Graham, R.M.; Mintz, K.J.; Zhou, Y.; Vanni, S.; Peng, Z.; Leblanc, R.M. Triple conjugated carbon dots as a nano-drug delivery model for glioblastoma brain tumors. Nanoscale 2019, 11, 6192-6205. [CrossRef]

66. Li, S.; Amat, D.; Peng, Z.; Vanni, S.; Raskin, S.; de Angulo, G.; Othman, A.M.; Graham, R.M.; Leblanc, R.M. Transferrin conjugated nontoxic carbon dots for doxorubicin delivery to target pediatric brain tumor cells. Nanoscale 2016, 8, 16662-16669. [CrossRef]

67. Zhou, Y.; Liyanage, P.Y.; Geleroff, D.L.; Peng, Z.; Mintz, K.J.; Hettiarachchi, S.D.; Pandey, R.R.; Chusuei, C.C.; Blackwelder, P.L.; Leblanc, R.M. Photoluminescent carbon dots: A mixture of heterogeneous fractions. Chem. Phys. Chem. 2018, 19, 2589-2597. [CrossRef]

68. Gao, F.; Ma, S.; Li, J.; Dai, K.; Xiao, X.; Zhao, D.; Gong, W. Rational design of high quality citric acid-derived carbon dots by selecting efficient chemical structure motifs. Carbon 2017, 112, 131-141. [CrossRef] 
69. Zhang, Y.; Rong, Q.; Zhao, J.; Zhang, J.; Zhu, Z.; Liu, Q. Boron-doped graphene quantum dot/Ag-LaFeO 3 $\mathrm{p}-\mathrm{p}$ heterojunctions for sensitive and selective benzene detection. J. Mater. Chem. A 2018, 6, 12647-12653. [CrossRef]

70. Bourlinos, A.B.; Trivizas, G.; Karakassides, M.A.; Baikousi, M.; Kouloumpis, A.; Gournis, D.; Bakandritsos, A.; Hola, K.; Kozak, O.; Zboril, R. Green and simple route toward boron doped carbon dots with significantly enhanced non-linear optical properties. Carbon 2015, 83, 173-179. [CrossRef]

71. Zhou, Y.; Desserre, A.; Sharma, S.K.; Li, S.; Marksberry, M.H.; Chusuei, C.; Blackwelder, P.L.; Leblan, R.M.C. Gel-like carbon dots: Characterization and their potential applications. Chem. Phys. Chem. 2017, 18, 890-897. [CrossRef]

72. Gao, Z.; Wang, X.; Chang, J.; Wu, D.; Wang, L.; Liu, X.; Xu, F.; Guo, Y.; Jiang, K. Fluorescent carbon quantum dots, capacitance and catalysis active porous carbon microspheres from beer. RSC Adv. 2015, 5, 48665-48674. [CrossRef]

73. Ehrat, F.; Bhattacharyya, S.; Schneider, J.; Loöf, A.; Wyrwich, R.; Rogach, A.L.; Stolarczyk, J.K.; Urban, A.S.; Feldmann, J. Tracking the source of carbon dot photoluminescence: Aromatic domains versus molecular fluorophores. Nano Lett. 2017, 17, 7710-7716. [CrossRef] [PubMed]

74. Nabid, M.R.; Bide, Y.; Fereidouni, N. Boron and nitrogen co-doped carbon dots as a metal-free catalyst for hydrogen generation from sodium borohydride. New J. Chem. 2016, 40, 8823-8828. [CrossRef]

75. Hua, X.-W.; Bao, Y.-W.; Zeng, J.; Wu, F.-G. Nucleolus-targeted red emissive carbon dots with polarity-sensitive and excitation-independent fluorescence emission: High-resolution cell imaging and in vivo tracking. ACS Appl. Mater. Interfaces 2019, 11, 32647-32658. [CrossRef] [PubMed]

76. Dong, H.; Chen, Y.-C.; Feldmann, C. Polyol synthesis of nanoparticles: Status and options regarding metals, oxides, chalcogenides, and non-metal elements. Green Chem. 2015, 17, 4107-4132. [CrossRef]

77. Dong, H.; Roming, M.; Feldmann, C. Unexpected fluorescence of polyols and PEGylated nanoparticles derived from carbon dot formation. Part. Part. Syst. Char. 2015, 32, 467-475. [CrossRef]

78. Kumar, V.V.; Raman, T.; Anthony, S.P. Fluorescent carbon quantum dots chemosensor for selective turn-on sensing of $\mathrm{Zn}^{2+}$ and turn-off sensing of $\mathrm{Pb}^{2+}$ in aqueous medium and zebrafish eggs. New J. Chem. 2017, 41, 15157-15164. [CrossRef]

79. Lee, T.H.; Rabalais, J.W. X-ray photoelectron spectra and electronic structure of some diamine compounds. J. Electron. Spectrosc. Relat. Phenom. 1977, 11, 123-127. [CrossRef]

80. Xiong, Y.; Schneider, J.; Ushakova, E.V.; Rogach, A.L. Influence of molecular fluorophores on the research field of chemically synthesized carbon dots. Nano Today 2018, 23, 124-139. [CrossRef]

81. Zhu, S.J.; Meng, Q.N.; Wang, L.; Zhang, J.H.; Song, Y.B.; Jin, H.; Zhang, K.; Sun, H.C.; Wang, H.Y.; Yang, B. Highly photoluminescent carbon dots for multicolor patterning, sensors, and bioimaging. Angew. Chem. Int. Ed. 2013, 52, 3953-3957. [CrossRef]

82. Kasprzyk, W.; Świergosz, T.; Bednarz, S.; Walas, K.; Bashmakova, N.V.; Bogdał, D. Luminescence phenomena of carbon dots derived from citric acid and urea-a molecular insight. Nanoscale 2018, 10, 13889-13894. [CrossRef] [PubMed]

83. Ludmerczki, R.; Mura, S.; Carbonaro, C.M.; Mandity, I.M.; Carraro, M.; Senes, N.; Garroni, S.; Granozzi, G.; Calvillo, L.; Marras, S. Carbon dots from citric acid and its intermediates formed by thermal decomposition. Chem. Eur. J. 2019, 25, 11963-11974. [CrossRef] [PubMed]

84. Longo, A.; Sciortino, A.; Cannas, M.; Messina, F. UV photobleaching of carbon nanodots investigated by in situ optical methods. Phys. Chem. Chem. Phys. 2020, 22, 13398-13407. [CrossRef] [PubMed]

85. Ehtesabi, H.; Hallaji, Z.; Nobar, S.N.; Bagheri, Z. Carbon dots with pH-responsive fluorescence: A review on synthesis and cell biological applications. Microchim. Acta 2020, 187, 150. [CrossRef]

86. Meierhofer, F.; Dissinger, F.; Weigert, F.; Jungclaus, J.; Muüller-Caspary, K.; Waldvogel, S.R.; Resch-Genger, U.; Voss, T. Citric acid based carbon dots with amine type stabilizers: $\mathrm{pH}$-specific luminescence and quantum yield characteristics. J. Phys. Chem. C 2020, 124, 8894-8904. [CrossRef]

87. Lu, C.; Su, Q.; Yang, X. Ultra-long room-temperature phosphorescent carbon dots: pH sensing and dual-channel detection of tetracyclines. Nanoscale 2019, 11, 16036-16042. [CrossRef]

88. Zhang, Y.; Hu, Y.; Zhao, J.; Park, E.; Jin, Y.; Liu, Q.; Zhang, W. Covalent organic framework-supported Fe-TiO 2 nanoparticles as ambient-light-active photocatalysts. J. Mater. Chem. A 2019, 7, 16364-16371. [CrossRef] 
89. Peng, F.; Gao, H.; Zhang, G.; Zhu, Z.; Zhang, J.; Liu, Q. Synergistic effects of Sm and C co-doped mixed phase crystalline $\mathrm{TiO}_{2}$ for visible light photocatalytic activity. Materials 2017, 10, 209. [CrossRef]

90. Cai, X.Y.; Liu, Y.J.; Zeng, H.; Cai, Y.; Li, H.; Zhang, F.; Wang, Y.D. Synthesis and characterisation of alkali metal (Mn, Fe) oxide-ZnO nanorod composites and their photocatalytic decolourization of rhodamine B under visible light. Mater. Technol. 2012, 27, 380-387. [CrossRef]

91. Kumar, K.V.; Porkodi, K.; Rocha, F. Langmuir-Hinshelwood kinetics-a theoretical study. Catal. Commun. 2008, 9, 82-84. [CrossRef]

92. Hu, S.; Tian, R.; Dong, Y.; Yang, J.; Liu, J.; Chang, Q. Modulation and effects of surface groups on photoluminescence and photocatalytic activity of carbon dots. Nanoscale 2013, 5, 11665-11671. [CrossRef] [PubMed]

(C) 2020 by the authors. Licensee MDPI, Basel, Switzerland. This article is an open access article distributed under the terms and conditions of the Creative Commons Attribution (CC BY) license (http://creativecommons.org/licenses/by/4.0/). 